\title{
Karakteristik Mikrobiologis Kombucha Dari Berbagai Jenis Olahan Teh
}

\author{
YULI FEBRIANTI ${ }^{1}$, RENI DWI RIASTUTI ${ }^{1}$ \\ ${ }^{1}$ Jurusan Pendidikan Matematika dan Ilmu Pengetahuan Alam, STKIP-PGRI Lubuklinggau \\ Jl. Mayor Toha Kelurahan Air Kuti, Lubuklinggau Timur I, Lubuklinggau, Sumatera Selatan 31626 \\ email: yuli_febri.anti16@yahoo.co.id
}

\begin{abstract}
This research aimed to analyze microbiological characteristics of kombucha from various types of tea processing which tasty to drink and gave benefits to examine some types of diseases. This research used an experimental method. The kombucha microbiology of old and new colonies were analyzed quantitatively descriptive by Levene homogeneity test, Kolmogorov-Smirnov normality test, and Shapiro-Wilk test. It was continued by Kruskal-Wallis and Mann-Whitney test. The results of data analysis were the average thickness, wet weight and diameter by using Kruskal-Wallis test that the provision of various types of processed tea was significantly different with the wet weight $(0.222<0.05)$ but it was not significantly different to the thickness $(0.170>0.05)$ and diameter $(0.637>0.05)$ the old kombucha colony. Furthermore, Mann-Whitney test obtained was significant ( $p$-value $)>0.05$. It was showed that it was not significantly different to the average data wet weight of old kombucha colony. In addition, It was significantly different to various type of tea processing to the thickness $(0.015<0.05)$ fresh weight $(0.017<0.05)$, diameter $(0.046<0.05)$, and the sheet $(0.042<0.05)$ new kombucha colony. Furthermore, Mann-Whitney test obtained was significant ( $p$-value $)>0.05$. It means that it was not significantly effective to the average data of thickness, wet weight, diameter, sheet new kombucha colonies. The best treatment was administrating of green tea (P3) in the old and new kombucha colonies were significantly different from other treatments.
\end{abstract}

Keywords: kombucha, microbiological, processed tea

\section{INTISARI}

Penelitian ini bertujuan untuk menganalisis karakteristik mikrobiologis kombucha dari berbagai jenis olahan teh yang nikmat untuk diminum dan berkhasiat untuk mengobati berbagai penyakit. Penelitian ini menggunakan metode eksperimen. Mikrobiologis kombucha koloni lama dan koloni baru yang dianalisis secara deskriptif kuantitatif dengan uji homogenitas Levene dan uji normalitas Kolmogorov-Smirnov dan uji Shapiro-Wilk. Kemudian dilanjutkan dengan uji Kruskal-Wallis dan uji Mann-Whitney. Hasil analisis data rata-rata ketebalan, berat basah, dan diameter dengan menggunakan uji Kruskal-Wallis bahwa pemberian berbagai jenis olahan teh berbeda nyata terhadap berat basah $(0,022<0,05)$ tetapi tidak berbeda nyata terhadap ketebalan $(0,170>0,05)$ dan diameter $(0,637>0,05)$ kombucha koloni lama. Selanjutnya uji Mann-Whitney didapat signifikan ( $\mathrm{p}$-value) $>0,05$ berarti data rata-rata berat basah kombucha koloni lama tidak ada perbedaan yang signifikan. Pemberian berbagai jenis olahan teh berbeda nyata terhadap ketebalan $(0,015<0,05)$, berat basah $(0,017<0,05)$, diameter $(0,046<0,05)$, dan lembaran $(0,042<0,05)$ kombucha koloni baru. Selanjutnya uji Mann-Whitney didapat signifikan ( $p$-value) $>0,05$ berarti data rata-rata ketebalan, berat basah, diameter, lembaran kombucha koloni baru tidak ada perbedaan yang signifikan. Perlakuan terbaik yaitu pemberian teh hijau (P3) pada kombucha koloni lama dan kombucha koloni baru yang berbeda nyata dengan perlakuan yang lainnya.

Kata Kunci: kombucha, mikrobiologis, olahan teh

\section{PENDAHULUAN}

Departemen kesehatan menganjurkan masyarakat untuk back to nature (kembali ke obat tradisional) adalah tepat karena harga obat-obatan yang mahal. Bahan obat tradisional mudah didapat, murah (terjangkau 
oleh seluruh lapisan masyarakat) dan dapat dibuat oleh semua orang. Teh merupakan bahan minuman yang secara universal dikonsumsi di banyak negara serta di berbagai lapisan masyarakat. Teh hitam diproduksi oleh lebih dari $75 \%$ negara di dunia, sedangkan teh hijau di produksi kurang lebih di 22\% negara di dunia. Selain itu di negaranegara Barat, lebih dari setengah asupan flavonoid berasal dari teh hitam. Teh merupakan salah satu bahan minuman alami yang sangat populer di masyarakat. Kandungan flavonoid dalam teh merupakan antioksidan yang bersifat antikarsinogenik, kariostatik serta hipokolesterolemik. Beberapa peneliti lain juga menyebutkan bahwa teh dapat bekerja sebagai hipoglikemik dan dapat menghambat aterosklerosis (Setyamidjaja, 2008).

Kombucha masih asing di masyarakat Indonesia. Kombucha hidup pada medium larutan teh manis yang sebenarnya sudah digunakan manusia selama berabad-abad. Sampai saat ini kombucha masih digunakan karena khasiatnya seperti membuat tubuh sehat dan bugar. Kombucha mengolah air teh dan gula menjadi zat-zat yang berguna bagi kesehatan tubuh. Menurut ahli kesehatan, teh kombucha mengandung vitamin B kompleks dan asam folat. Kombucha memiliki kemampuan dan vitalitas untuk tumbuh sehingga jamur kombucha ini hidup ribuan tahun sampai sekarang (Naland, 2008).

Dalam pembuatan teh kombucha terjadi proses perubahan gula menjadi beberapa komponen antara lain adalah asam-asam organik. Teh kombucha mempengaruhi tubuh secara menyeluruh, dengan menstabilkan metabolisme tubuh dan detoksifikasi racun dengan asam glukoronat. Hal ini menyebabkan peningkatan kapasitas pertahanan dalam tubuh terhadap pengaruh dan tekanan lingkungan. Potensi teh kombucha untuk kesehatan perlu didukung dengan penelitian ilmiah. Kajian praklinis akan memberikan data yang mencakup inhibisi teh kombucha terhadap aktifitas xantin oksidase. Xantin oksidase merupakan enzim yang berperan penting dalam pembentukan asam urat (Anandagiri dkk.,
2014). Komposisi pucuk daun teh yang banyak mengandung zat-zat yang larut dalam air, seperti katekin (polifenol), asam amino, dan gula sangat cocok sebagai medium kombucha yang mengubah zat-zat tersebut menjadi senyawa kimia lain yang bermanfaat bagi tubuh seperti mengobati nyeri persendian, kolesterol tinggi, hipertensi, buang air kecil, asma, dan sendi kronis (Naland, 2008).

Penelitian ilmiah Nainggolan (2009) membuktikan bahwa fermentasi kombucharosela merah yang divariasikan dengan kadar gula dan lama fermentasi, mempengaruhi pertumbuhan bakteri Acetobacter sp., produksi nata yang dihasilkan, total asam yang dihasilkan, $\mathrm{pH}$, kadar alkohol, dan Total Soluble Solid (TSS).

Berdasarkan hal tersebut, maka dilakukan penelitian untuk mengamati karakteristik mikrobiologis kombucha dari berbagai jenis olahan teh yaitu teh putih (P1), teh hitam (P2), teh hijau (P3), dan teh oolong (P4) yang kemudian menjadi perbandingan dengan penelitian yang sudah dilakukan, baik dari persamaan atau perbedaan kombucha yang dihasilkan.

\section{METODE}

Penelitian ini menggunakan metode eksperimen dengan lima perlakuan $(\mathrm{P}=5)$ dan empat pengulangan $(n=4)$. Data mikrobiologis kombucha yaitu ketebalan, berat basah, diameter, dan lembaran kombucha dengan menggunakan program Statistical Package for the Social Sciences (SPSS) Statistic 17.0. Data mikrobiologis kombucha dianalisis secara deskriptif kuantitatif dengan uji homogenitas Levene dan uji normalitas Kolmogorov-Smirnov dan uji Shapiro-Wilk. Kemudian dilanjutkan dengan uji KruskalWallis dan uji Mann Whitney. Data akhir mikrobiologis kombucha (ketebalan kombucha, berat basah kombucha, diameter) dikurang dengan data awal yaitu diukur dengan menggunakan jangka sorong dan timbangan (Nainggolan, 2009).

Adapun proses pembuatan medium kombucha yaitu tahap persiapan medium, tahap inokulasi dan tahap inkubasi. Air 
direbus hingga mendidih $\left(100^{\circ} \mathrm{C}\right)$ selama 30 menit. Sebanyak $300 \mathrm{ml}$ air dimasukkan 3 gram teh putih, teh hitam, teh hijau, dan teh oolong, teh tersebut diseduh selama 15 menit dan disaring untuk memisahkan ampasnya, setelah itu ditambahkan 30 gram gula, dilarutkan sampai homogen dan didinginkan sampai suhu ruang $\left( \pm 23^{\circ} \mathrm{C}-27^{\circ} \mathrm{C}\right)$, kemudian dimasukkan dalam wadah fermentasi. Inokulasi kultur kombucha dalam air bibit kombucha, ditutup dengan kain dan diikat dengan karet gelang, fermentasi selama 28 hari, kemudian karakteristik mikrobiologis

Tabel 1. Analisis ketebalan kombucha koloni lama

\begin{tabular}{cc}
\hline Perlakuan & Ketebalan Rata-rata \pm SD (cm) \\
\hline Kontrol (P0) & $0,1225 \pm 0,0350$ \\
Teh Putih (P1) & $0,0550 \pm 0,0341$ \\
\hline Teh Hitam (P2) & $0,0675 \pm 0,0518$ \\
\hline Teh Hijau (P3) & $0,0900 \pm 0,0535$ \\
\hline Teh Oolong (P4) & $0,0500 \pm 0,1155$ \\
\hline
\end{tabular}

Berdasarkan Tabel 1, rata-rata ketebalan kombucha lama pada P0 lebih tinggi daripada rata-rata ketebalan kombucha lama pada $\mathrm{P} 1$, P2, P3, dan P4. Hal ini menunjukkan bahwa dengan air gula tanpa pemberian berbagai olahan teh cenderung berpeluang untuk menaikkan ketebalan kombucha koloni lama. Hasil uji normalitas Kolmogorov-Smirnov dan uji Shapiro-Wilk diperoleh nilai signifikan P0, P1, P2, P3, dan P4 $<0,05$ menunjukkan data rata-rata ketebalan kombucha koloni lama tidak berdistribusi kombucha dari berbagai jenis olahan teh dianalisis (Naland, 2008).

\section{HASIL}

Analisis mikrobiologis kombucha koloni lama dari berbagai jenis olahan teh. Kombucha difermentasi selama 28 hari, kemudian ditiriskan selama 10 menit dan dilakukan pengukuran ketebalan, berat basah, dan diameter kombucha koloni lama. Adapun analisis mikrobiologis kombucha koloni lama dari berbagai jenis olahan teh terlihat di tabel 1 .

Tabel 2. Analisis berat basah kombucha koloni lama

\begin{tabular}{cc}
\hline Perlakuan & Berat Basah Rata-rata \pm SD (g) \\
\hline Kontrol (P0) & $0,5000 \pm 1,0000$ \\
\hline Teh Putih (P1) & $0,7500 \pm 1,5000$ \\
\hline Teh Hitam (P2) & $0,0000 \pm 0,0000$ \\
\hline Teh Hijau (P3) & $3,0000 \pm 1,4140$ \\
\hline Teh Oolong (P4) & $1,5000 \pm 1,0000$ \\
\hline
\end{tabular}

Berdasarkan Tabel 2, menunjukkan bahwa rata-rata berat basah kombucha lama pada P3 lebih berat daripada rata-rata berat basah kombucha lama pada P0, P1, P2, dan P4. Pemberian teh hijau dapat berpeluang untuk menaikkan berat basah kombucha koloni lama. Hasil uji normalitas normal. Hasil uji homogenitas Levene $(0,020$ $<0,05)$ menunjukkan data rata-rata ketebalan kombucha koloni lama tidak berdistribusi homogen.

Berdasarkan hasil kedua uji tersebut, maka data rata-rata ketebalan kombucha koloni lama selanjutnya diuji dengan uji Kruskal-Wallis. Hasil uji Kruskal-Wallis $(0,170>0,05)$ menunjukkan data rata-rata ketebalan kombucha koloni lama cenderung naik tetapi tidak berbeda nyata (tidak ada perbedaan yang bermakna).
Kolmogorov-Smirnov dan uji Shapiro-Wilk diperoleh nilai signifikan P0, P1, P2, P3, dan $\mathrm{P} 4<0,05$ menunjukkan data rata-rata berat basah kombucha koloni lama tidak berdistribusi normal. Hasil uji homogenitas Levene $(0,118>0,05)$ menunjukkan bahwa data rata-rata berat basah kombucha koloni 
lama berdistribusi homogen. Berdasarkan hasil kedua uji tersebut, maka data rata-rata berat basah kombucha koloni lama selanjutnya diuji dengan uji Kruskal-Wallis. Hasil uji Kruskal-Wallis $(0,022<0,05)$ diperoleh data rata-rata berat basah kombucha koloni lama berpeluang untuk menaikkan berat basah kombucha koloni lama dan berbeda nyata (ada perbedaan yang bermakna). Selanjutnya uji Mann-Whitney diperoleh nilai signifikan $(p$-value $)>0,05$ menunjukkan bahwa data rata-rata berat basah kombucha koloni lama tidak ada perbedaan yang signifikan.

Tabel 3. Analisis diameter kombucha koloni lama

\begin{tabular}{cc}
\hline Perlakuan & Diameter Rata-rata \pm SD (cm) \\
\hline Kontrol (P0) & $1,6775 \pm 0,0298$ \\
\hline Teh Putih (P1) & $1,7100 \pm 0,3077$ \\
\hline Teh Hitam (P2) & $1,7275 \pm 0,1499$ \\
\hline Teh Hijau (P3) & $1,6225 \pm 0,1596$ \\
\hline Teh Oolong (P4) & $1,7575 \pm 0,1517$ \\
\hline
\end{tabular}

Berdasarkan Tabel 3, menunjukkan bahwa rata-rata diameter kombucha lama pada $\mathrm{P} 4$ lebih besar daripada rata-rata diameter kombucha lama pada P0, P1, P2, dan P4. Pemberian teh oolong (P4) dapat cenderung berpeluang untuk memperbesar diameter kombucha koloni lama. Hasil uji normalitas Kolmogorov-Smirnov dan uji Shapiro-Wilk diperoleh nilai signifikan P0, $\mathrm{P} 2$, P3, dan $\mathrm{P} 4<0,05$ menunjukkan bahwa data rata-rata ketebalan kombucha koloni lama tidak berdistribusi normal. Hasil uji homogenitas Levene $(0,085>0,05)$ menunjukkan bahwa data rata-rata kombucha koloni lama berdistribusi homogen. Berdasarkan hasil kedua uji tersebut, maka data rata-rata kombucha koloni lama selanjutnya diuji dengan uji Kruskal-Wallis. Hasil uji Kruskal-Wallis $(0,637>0,05)$ diperoleh data rata-rata diameter kombucha koloni lama cenderung berpeluang untuk memperbesar diameter kombucha koloni lama tetapi tidak berbeda nyata (tidak ada perbedaan yang bermakna).

Analisis mikrobiologis kombucha koloni baru dari berbagai jenis olahan teh. Kombucha difermentasi selama 28 hari, kemudian ditiriskan selama 10 menit dan dilakukan pengukuran ketebalan, berat basah, diameter, dan lembaran kombucha koloni baru. Adapun hasil analisis mikrobiologis kombucha koloni lama dari berbagai jenis olahan teh terlihat pada tabel 4 .

Tabel 4. Analisis ketebalan kombucha koloni baru

\begin{tabular}{cc}
\hline Perlakuan & Ketebalan Rata-rata \pm SD (cm) \\
\hline Kontrol (P0) & $0,2750 \pm 0,1206$ \\
\hline Teh Putih (P1) & $1,2925 \pm 0,4181$ \\
\hline Teh Hitam (P2) & $1,2475 \pm 0,1359$ \\
\hline Teh Hijau (P3) & $1,5750 \pm 0,2600$ \\
\hline Teh Oolong (P4) & $1,1725 \pm 0,2099$ \\
\hline
\end{tabular}

Berdasarkan Tabel 4, menunjukkan bahwa rata-rata ketebalan kombucha baru pada P3 lebih tinggi daripada rata-rata ketebalan kombucha baru pada P0, P1, P2, dan P4. Pemberian teh hijau dapat berpeluang untuk menaikkan ketebalan kombucha koloni baru. Hasil uji normalitas KolmogorovSmirnov dan uji Shapiro-Wilk diperoleh nilai signifikan P0, P1, P2, P3, dan P4 $<0,05$ menunjukkan bahwa data rata-rata ketebalan kombucha koloni baru tidak berdistribusi normal. Hasil uji homogenitas Levene $(0,273$ $>0,05)$ menunjukkan bahwa data rata-rata ketebalan kombucha koloni baru berdistribusi homogen. Berdasarkan hasil kedua uji tersebut, maka data rata-rata ketebalan 
kombucha koloni baru selanjutnya diuji dengan uji Kruskal-Wallis. Hasil uji KruskalWallis $(0,015<0,05)$ diperoleh data rata-rata ketebalan kombucha koloni baru dapat berpeluang untuk menaikkan ketebalan kombucha koloni baru dan berbeda nyata (ada perbedaan yang bermakna). Selanjutnya uji Mann-Whitney diperoleh nilai signifikan ( $p$ value $)>0,05$ menunjukkan bahwa data ratarata ketebalan kombucha koloni baru tidak ada perbedaan yang signifikan.

Tabel 5. Analisis berat basah kombucha koloni baru

\begin{tabular}{cc}
\hline Perlakuan & Berat Basah Rata-rata \pm SD $(\mathbf{g})$ \\
\hline Kontrol (P0) & $11,2500 \pm 6,2920$ \\
\hline Teh Putih (P1) & $65,0000 \pm 12,9100$ \\
\hline Teh Hitam (P2) & $61,7500 \pm 9,6050$ \\
\hline Teh Hijau (P3) & $74,7500 \pm 6,0760$ \\
\hline Teh Oolong (P4) & $58,7500 \pm 13,1500$ \\
\hline
\end{tabular}

Berdasarkan Tabel 5, menunjukkan bahwa rata-rata berat basah kombucha baru pada P3 lebih berat daripada rata-rata berat basah kombucha baru pada P0, P1, P2, dan P4. Pemberian teh hijau dapat berpeluang untuk menaikkan berat basah kombucha koloni baru. Hasil uji normalitas Kolmogorov-Smirnov dan uji Shapiro-Wilk didapat signifikan P0, P1, P2, P3,dan P4 < 0,05 menunjukkan bahwa data rata-rata ketebalan kombucha koloni baru tidak berdistribusi normal. Hasil uji homogenitas Levene $(0,489>0,05)$ menunjukkan bahwa data rata-rata berat basah kombucha koloni baru berdistribusi homogen. Berdasarkan hasil kedua uji tersebut, maka data rata-rata berat basah kombucha koloni baru selanjutnya diuji dengan uji Kruskal-Wallis. Hasil uji Kruskal-Wallis $(0,017<0,05)$ diperoleh data rata-rata berat basah kombucha koloni baru dapat berpeluang untuk menaikkan berat basah kombucha koloni baru dan berbeda nyata (ada perbedaan yang bermakna). Selanjutnya uji Mann-Whitney diperoleh nilai signifikan $(p$-value $)>0,05$ menunjukkan bahwa data rata-rata berat basah kombucha koloni baru tidak ada perbedaan yang signifikan.

Tabel 6. Analisis diameter kombucha koloni baru

\begin{tabular}{cc}
\hline Perlakuan & Diameter Rata-rata \pm SD (cm) \\
\hline Kontrol (P0) & $7,8900 \pm 0,8094$ \\
\hline Teh Putih (P1) & $8,5450 \pm 0,1922$ \\
\hline Teh Hitam (P2) & $8,5150 \pm 0,0988$ \\
\hline Teh Hijau (P3) & $8,8425 \pm 0,2651$ \\
\hline Teh Oolong (P4) & $8,6975 \pm 0,3549$ \\
\hline
\end{tabular}

Berdasarkan Tabel 6, rata-rata diameter kombucha koloni baru pada P3 lebih besar daripada rata-rata diameter kombucha baru pada P0, P1, P2, dan P4. Pemberian teh hijau dapat cenderung berpeluang untuk memperbesar diameter kombucha koloni baru. Hasil uji normalitas KolmogorovSmirnov dan uji Shapiro-Wilk diperoleh nilai signifikan pada P0, P1, P2, P3,dan P4 $<0,05$ menunjukkan bahwa data rata-rata diameter kombucha koloni baru tidak berdistribusi normal. Hasil uji homogenitas Levene $(0,032$
$<0,05)$ menunjukkan bahwa data rata-rata diameter kombucha koloni baru tidak berdistribusi homogen. Berdasarkan hasil kedua uji tersebut, maka data rata-rata diameter kombucha koloni baru selanjutnya diuji dengan uji Kruskal-Wallis. Hasil uji Kruskal-Wallis $(0,046<0,05)$ diperoleh data rata-rata diameter kombucha koloni baru dapat memperbesar diameter kombucha koloni lama berbeda nyata (ada perbedaan yang bermakna). Selanjutnya uji MannWhitney diperoleh nilai signifikan $(p$-value $)>$ 
0,05 menunjukkan bahwa data rata-rata

perbedaan yang signifikan.

diameter kombucha koloni baru tidak ada

Tabel 7. analisis lembaran kombucha koloni baru

\begin{tabular}{cc}
\hline Perlakuan & Lembaran Rata-rata \pm SD \\
\hline Kontrol (P0) & $1,0000 \pm 0,0000$ \\
\hline Teh Putih (P1) & $1,0000 \pm 0,0000$ \\
\hline Teh Hitam (P2) & $1,7500 \pm 0,5000$ \\
\hline Teh Hijau (P3) & $2,2500 \pm 0,9570$ \\
\hline Teh Oolong (P4) & $1,2500 \pm 0,5000$ \\
\hline
\end{tabular}

Berdasarkan Tabel 7, rata-rata lembaran kombucha koloni baru pada P3 dan P4 lebih banyak daripada rata-rata lembaran kombucha koloni baru pada P0, P1, dan P2. Pemberian teh hijau dan teh oolong dapat berpeluang untuk memperbanyak lembaran kombucha koloni baru. Hasil uji normalitas Kolmogorov-Smirnov dan uji Shapiro-Wilk diperoleh nilai signifikan pada P0, P1, P2, P3, dan $\mathrm{P} 4<0,05$ menunjukkan bahwa data ratarata lembaran kombucha koloni baru tidak berdistribusi normal. Hasil uji homogenitas Levene $(0,0030<0,05)$ menunjukkan bahwa data rata-rata lembaran kombucha koloni baru berdistribusi tidak homogen. Berdasarkan hasil kedua uji tersebut, maka data rata-rata lembaran kombucha koloni baru selanjutnya diuji dengan uji Kruskal-Wallis. Hasil uji Kruskal-Wallis $(0,042<0,05)$ diperoleh data rata-rata lembaran kombucha koloni baru dapat berpeluang untuk memperbanyak lembaran kombucha koloni baru dan berbeda nyata (ada perbedaan yang bermakna). Selanjutnya uji Mann-Whitney diperoleh nilai signifikan $(p$-value $)>0,05$ menunjukkan bahwa data rata-rata lembaran kombucha koloni baru tidak ada perbedaan yang signifikan.

\section{PEMBAHASAN}

Ketebalan kombucha koloni lama dari berbagai jenis olahan teh pada akhir fermentasi menunjukkan ketebalan yang cenderung berbeda. Pemberian dengan air gula (P0) tanpa pemberian berbagai olahan teh cenderung berpeluang menaikkan ketebalan kombucha koloni lama. Berdasarkan hal tersebut, tidak terdapat perbedaan yang bermakna antara kontrol (P0), teh putih (P1), teh hitam (P2), teh hijau (P3), dan teh oolong (P4). Hal ini diduga karena tingginya pertambahan ketebalan pada lembaran koloni lama jamur kombucha pada perlakuan tanpa teh (kontrol) tidak memiliki gelatinoid (gel) yang banyak sehingga zat makanan atau nutrisi yang terdapat pada kombucha hanya digunakan oleh satu lembaran kombucha koloni lama yang pertama dan satu lagi pada lembaran kombucha koloni baru. Lapisan-lapisan gelatinoid dan membran kombucha merupakan penyusun kombucha yang menyebabkan bertambahnya ketebalan kombucha koloni lama. Selain itu berkurangnya nutrisi dan lama fermentasi untuk kombucha koloni lama yang mengakibatkan ketebalan kombucha koloni lama yang cenderung berbeda. Sesuai dengan pernyataan Fiana dkk., (2006) bahwa peningkatan kadar asam laktat, kadar vitamin $\mathrm{C}$, antioksidan dan polifenol dari larutan teh menjadi teh kombucha pada proses fermentasi. Selanjutnya penelitian Jasman and Widianto (2012) bahwa semakin lama waktu fermentasi, maka akan semakin banyak asam asetat yang terbentuk sebagai hasil metabolisme Acetobacter xylinum. Semakin lama fermentasi, maka hasil fermentasi semakin asam.

Berat basah kombucha koloni lama dari berbagai jenis olahan teh pada akhir fermentasi menunjukkan bahwa pemberian teh hijau (P3) dapat berpeluang untuk menaikkan berat basah kombucha koloni lama. Terdapat perbedaan yang nyata (perbedaan yang bermakna) antara kontrol (P0), teh putih (P1), teh hitam (P2), teh hijau (P3) dan teh oolong (P4) diduga karena 
tingginya pertambahan berat basah pada teh hijau (P3) yang banyak mengandung selulosa, mineral, bahan yang dapat mengendapkan alkohol dan sedikit mengandung kafein dibandingkan dengan teh putih (P1), teh hitam (P2), dan teh oolong (P4) sehingga membuat pertambahan berat basah pada kombucha koloni lama. Hal ini sesuai dengan penelitian Nainggolan (2009), pertambahan ukuran berat pada lapisan kombucha semakin naik seiring dengan penambahan waktu dan banyaknya kadar gula di dalam larutan sebagai sumber energi.

Diameter kombucha koloni lama dari berbagai jenis olahan teh pada akhir fermentasi menunjukkan bahwa pemberian teh oolong (P4) dapat cenderung berpeluang untuk memperbesar diameter kombucha koloni lama. Tidak terdapat perbedaan yang nyata (tidak ada perbedaan yang bermakna) antara kontrol (P0), teh putih (P1), teh hitam (P2), teh hijau (P3) dan teh oolong (P4) diduga karena di dalam teh oolong kombucha koloni lama memiliki sedikit lembaran kombucha koloni baru dibandingkan dengan teh hitam dan teh hijau sehingga satu lembaran kombucha mendapatkan cukup banyak nutrisi meskipun nutrisi terbagi pada lembaran kombucha koloni baru yang lain, oleh sebab itu pada teh oolong lembaran kombucha mengalami pelebaran diameter. Hal ini sesuai dengan hasil penelitian Nainggolan (2009) bahwa semakin baik pertumbuhan kombucha dalam larutan maka akan menaikkan produksi selulosa yang terbentuk.

Ketebalan kombucha koloni baru dari berbagai jenis olahan teh pada akhir fermentasi menunjukkan bahwa pemberian teh hijau (P3) dapat berpeluang untuk menaikkan ketebalan kombucha koloni baru. Terdapat perbedaan yang nyata (perbedaan yang bermakna) antara kontrol (P0), teh putih (P1), teh hitam (P2), teh hijau (P3) dan teh oolong (P4) diduga karena teh hijau banyak mengandung gula dan mineral yang akan meningkatkan ketebalan kombucha koloni baru. Semakin lama waktu fermentasi maka nutrisi dalam larutan teh akan habis dimanfaatkan oleh bakteri dan khamir untuk proses metabolisme dan membentuk koloni baru yang menyebabkan bertambahnya ketebalan kombucha. Hal ini sesuai dengan pernyataan Naland (2009) bahwa ketebalan kombucha yang terbentuk, bergantung pada faktor-faktor yaitu jangka waktu fermentasi, volume bibit dan starter yang digunakan, serta kondisi pH yang sesuai. Hasil penelitian Wistiana dan Zubaidah (2015) bahwa ketebalan nata dari semua sampel kombucha pada akhir fermentasi menunjukkan ketebalan yang berbeda. Selanjutnya hasil analisis ragam berbeda nyata $(\alpha=0,05)$ oleh Suhardini dan Zubaidah (2016) diduga karena semakin lama waktu fermentasi maka nutrisi yang terdapat dalam larutan teh akan habis dimanfaatkan oleh bakteri dan khamir untuk proses metabolisme dan membentuk koloni baru yang menyebabkan ketebalan nata.

Berat basah kombucha koloni baru dari berbagai jenis olahan teh pada akhir fermentasi menunjukkan bahwa pemberian teh hijau (P3) dapat berpeluang untuk menaikkan berat basah kombucha koloni baru. Terdapat perbedaan yang nyata (perbedaan yang bermakna) antara kontrol (P0), teh putih (P1), teh hitam (P2), teh hijau (P3) dan teh oolong (P4) diduga karena teh hijau banyak mengandung nutrisi yang dibutuhkan oleh lembaran kombucha seperti selulosa, asam amino, gula dan sedikit mengandung kafein dibandingkan dengan tanpa teh (P0), teh putih (P1), teh hitam (P2), dan teh oolong (P4) sehingga dengan banyaknya zat tersebut akan membuat kombucha bertambah berat. Hal ini sesuai dengan pernyataan Nainggolan (2009), berat ringannya lapisan kombucha yang terbentuk pada suatu perlakuan bergantung pada kelengkapan nutrien.

Diameter kombucha koloni baru dari berbagai jenis olahan teh pada akhir fermentasi menunjukkan bahwa pemberian teh hijau (P3) berpeluang untuk memperbesar diameter kombucha koloni baru. Terdapat perbedaan yang nyata (ada perbedaan yang bermakna) antara kontrol (P0), teh putih (P1), teh hitam (P2), teh hijau (P3) dan teh oolong (P4) diduga karena teh hijau kombucha koloni baru mendapatkan cukup banyak zat makanan 
atau nutrisi meskipun membagikan zat makanan atau nutrisi pada lembaran kombucha koloni baru yang lain, oleh sebab itu pada teh hijau kombucha koloni baru yang mengalami pelebaran diameter. Menurut Naland (2008), sifat kombucha yang seperti gel membuat bentuk kombucha mengikuti bentuk wadah atau tempat pembiakan. Hal ini sesuai dengan pernyataan Nainggolan (2009), tebal tipisnya lapisan kombucha atau selulosa yang terbentuk pada suatu perlakuan tergantung pada kelengkapan nutrien.

Lembaran kombucha koloni baru dari berbagai jenis olahan teh pada akhir fermentasi menunjukkan meningkatnya jumlah lembaran kombucha. Pemberian teh hijau (P3) dan teh oolong (P4) dapat berpeluang untuk meningkatkan jumlah lembaran kombucha koloni baru. Terdapat perbedaan yang nyata (perbedaan yang bermakna) antara kontrol (P0), teh putih (P1), teh hitam (P2), teh hijau (P3) dan teh oolong (P4) diduga karena teh hijau (P3) dan teh oolong (P4) memiliki nutrisi yang melimpah yaitu gula, kalium, katekin atau polifenol. Hal ini sesuai dengan pernyataan Nainggolan (2009), kelangsungan hidup kombucha memerlukan substrat, seperti larutan teh dan sumber karbon berupa gula. Setelah proses fermentasi, pada substrat terlihat lembaran mengapung di permukaan larutan yang menunjukkan telah terjadi perbanyakan (reproduksi) dari individu (inang), dan di akhir reproduksi terjadi proses metabolisme yang dapat mengubah sukrosa menjadi lapisan selulosa. Nutrisi merupakan sumber karbon untuk kelangsungan hidup kombucha. Jika nutrisi melimpah, maka pertumbuhan akan berlangsung dengan baik dan bila nutrisi telah habis, maka pertumbuhan terhenti, akan tetapi kombucha tetap dalam keadaan hidup.

\section{KESIMPULAN}

1. Pemberian berbagai jenis olahan teh berbeda nyata (perbedaan yang bermakna) terhadap berat basah tetapi tidak berbeda nyata terhadap ketebalan dan diameter kombucha koloni lama.

2. Pemberian berbagai jenis olahan teh berbeda nyata (perbedaan yang bermakna) terhadap ketebalan, berat basah, diameter, dan lembaran kombucha koloni baru.

3. Perlakuan terbaik yaitu pemberian teh hijau (P3) pada kombucha koloni lama dan kombucha koloni baru yang berbeda nyata (perbedaan yang bermakna) dengan perlakuan yang lainnya.

\section{DAFTAR PUSTAKA}

Anandagiri DAWM, Manuaba IBP, dan Suastuti Ni GAMDA. 2014. Pemanfaatan Teh Kombucha sebagai Obat Hiperurisemia melalui Penghambatan Aktifitas Xantin Oksidase pada Rattus norvegicus. Jurnal Kimia. vol 8(2): 220225.

Fiana RM, Murtius WS, Asben Alfi. 2016. Pengaruh Konsentrasi Maltodekstrin terhadap Mutu Minuman Instan dari Teh Kombucha. Jurnal Teknologi Pertanian Andalas. vol 20(2):1-8.

Jasman ID and Widianto D. 2012. Selection of Yeast Strains for Ethanol Fermentation of Glucose-Fructose-Sucrose Mixture. Journal of Biotechnology. vol 17(2):114120.

Nainggolan J. 2009. Kajian Pertumbuhan Bakteri Acetobakter sp. dalam Kombucha-Rosela Merah (Hibiscus sabdariffa) pada Kadar Gula dan Lama Fermentasi yang Berbeda. [Tesis]. Medan: Universitas Sumatera Utara.

Naland H. 2008. Kombucha Teh dengan Seribu Khasiat. Jakarta: Agromedia Pustaka. hal 2-60.

Setyamidjaja D. 2008. Teh Budidaya dan Pengolahan Pascapanen. Yogyakarta: Kanisius. hal 122-147.

Suhardini PN dan Zubaidah E. 2016. Studi Aktivitas Antioksidan Kombucha dari Berbagai Jenis Daun Selama Fermentasi. Jurnal Pangan dan Agroindustri. vol 4(1): 221-229.

Wistiana D dan Zubaidah E. 2015. Karakteristik kimiawi dan Mikrobiologis Kombucha dari Berbagai Daun Tinggi Fenol Selama Fermentasi. Jurnal Pangan dan Agroindustri. vol 3(4): 1446-1457. 